\title{
Giant tuberculous pseudocarcinomatous hyperplasia of fallopian tube mimicking ovarian neoplasm - A challenging diagnosis
}

\author{
Richa Sharma, Vishnu Bhartiya \\ Department of Obstetrics \& Gynecology, University College of Medical Sciences and Guru Teg Bahadur Hospital, Delhi, India
}

Received: January 7, 2017

DOI: $10.5430 /$ ijdi.v4n2p39

\author{
Accepted: February 7, 2017 \\ Online Published: May 17, 2017 \\ URL: https://doi.org/10.5430/ijdi.v4n2p39
}

\begin{abstract}
Pseudocarcinomatous hyperplasia of the fallopian tubes is an incidental histopathological finding or it causes slight enlargement of tubes. We are reporting a case where 38 years old woman reported with lump abdomen (corresponding to 28 weeks gravid uterus) and hypomenorrhea, was diagnosed as ovarian neoplasm after extensive work up that included tumor markers and CT scan. Staging laprotomy was undertaken, but intraoperatively it revealed massive enlargement of both the tubes. Frozen section and histopathological examination showed tuberculous pseudocarcinomatous hyperplasia of fallopian tubes. Bilateral salpingectomy was done. We are reporting this case because of its rarity, where massive enlargement of both the tubes was due to tuberculous Pseudocarcinomatous hyperplasia that mimicked ovarian neoplasm on clinical examination and on radioimaging techniques.
\end{abstract}

Key Words: Fallopian tubal hyperplasia, Pseudocarcinomatous hyperplasia, Incidental finding

\section{INTRODUCTION}

Hyperplasia is the abnormal increase in the number of cells in a tissue or organ which ultimately causes the enlargement of the organ or a part. Fallopian tubal hyperplasia is also called pseudocarcinomatous hyperplasia that typically is an incidental histopathological finding occurring with estrogen producing ovarian tumors or chronic pelvic inflammatory diseases or salpingitis..$^{[1,2]}$

Tuberculous salpingitis can cause benign proliferative and reactive processes of the tube and leads to florid form of epithelial hyperplasia with atypical features termed as "pseudocarcinomatous hyperplasia" that can mimic adenocarcinoma of tubes. Usually it causes no or slight enlargement of tubes, but enlargement of tubes to a extent that it becomes an abdominopelvic mass is extremely rare. Tuberculous pseudocarcinomatous hyperplasia of fallopian should always be considered for differential diagnosis of abdominopelvic mass, particularly in tropical countries like India. The incidence of female genital tuberculosis is $1 \%-2 \%$, occurring in women of reproductive age groups and usually asymptomatic but may present with low grade fever, menstrual irregularities, pelvic pain and infertility. ${ }^{[3]}$ Primary TB of the tubes are extremely rare. ${ }^{[4]}$

We are reporting a case where pseudocarcinomatous hyperplasia due to tubal Tuberculosis caused extensive enlargement of both the tubes that mimicked an ovarian neoplasm

\footnotetext{
* Correspondence: Richa Sharma, MD; Email: gautamdrricha1@ gmail.com; Address: Department of Obstetrics \& Gynecology, University College of Medical Sciences and Guru Teg Bahadur Hospital, Delhi-110095, India.
} 
and posed a diagnostic dilemma.

\section{CASe Report}

A 38 years woman presented with hypomonerrhoea and lump abdomen since 6 months. She had history of anorexia and weight loss. On examination mild pallor was present and other general physical, cardio-respiratory examinations were normal. Per abdomen revealed a firm to cystic mass corresponding to 28 weeks gravid uterus arising from pelvis, non tender with restricted mobility. On investigations, her $\mathrm{Hb}$ was $9 \mathrm{gm} \%$, TLC/DLC/KFT/LFT/TSH was normal, CA125 was $521 \mathrm{U} / \mathrm{ml}$ and other tumor markers were normal. Chest $\mathrm{x}$ ray and ECG were also normal. Ultrasonography showed normal sized uterus, right adnexal mass measuring $15 \mathrm{~cm} \times 13 \mathrm{~cm}$ with internal septations of $6 \mathrm{~mm}$ thickness, no increased flow, bilateral ovaries not visualized and mild free fluid was present (see Figure 1). CECT abdomen was suggestive of multiseptated well defined $15 \mathrm{~cm} \times 11 \mathrm{~cm}$ cystic mass in abdomen -pelvis with non visualization of both the ovaries, most likely bilateral ovarian neoplasm. She was taken up for staging laprotomy but intraoperatively a 13 $\mathrm{cm} \times 10 \mathrm{~cm}$ tubal mass on right side and $8 \mathrm{~cm} \times 5 \mathrm{~cm}$ tubal mass on left was found, both ovaries were normal, no other abnormality was found and ascetic fluid was sent for analysis (see Figure 2).

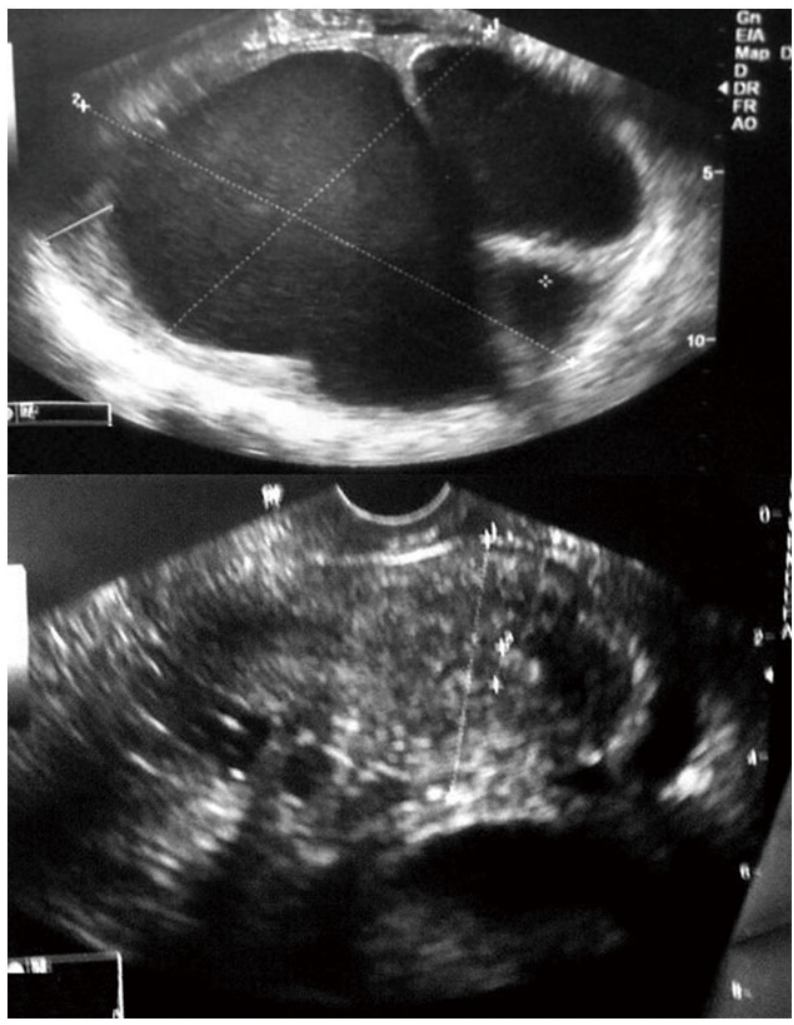

Figure 1. Transvaginal ultrasound showing right adnexal mass with non visualization of both ovaries

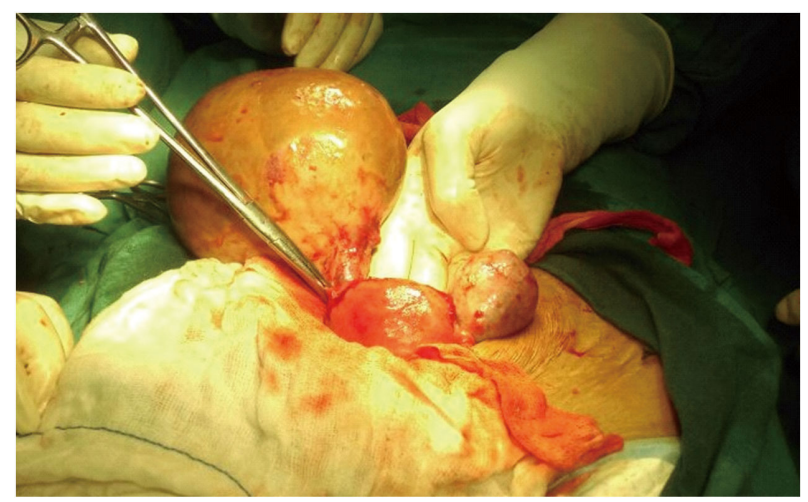

Figure 2. Intraoperative picture showing bilateral enlargement of tubes with normal ovaries

Frozen section revealed tuberculous salpingitis so bilateral salpingectomy was done. Cut section showed marked hypertrophy of both tubes with few tubercles and haemorrhagic fluid (see Figure 3).

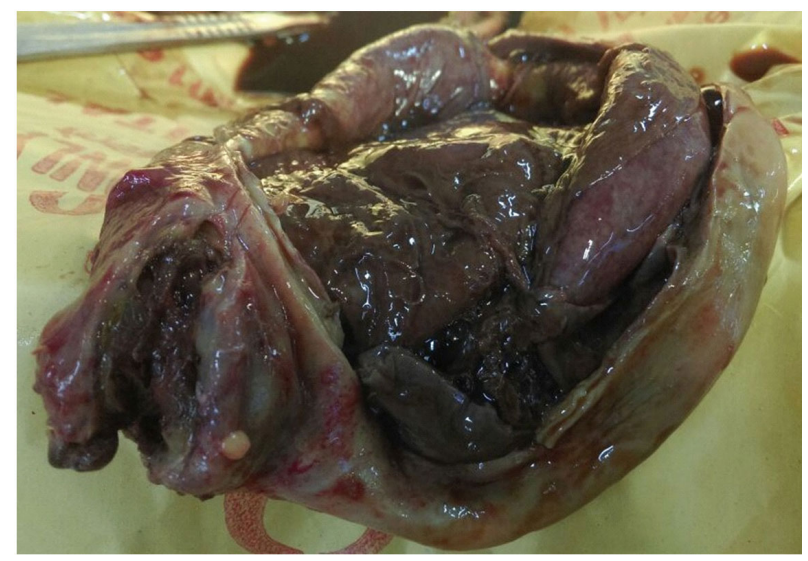

Figure 3. Cut section of tube

Histopathologial examination showed the features of pseudocarcinomatous hyperplasia of fallopian tubes, where marked mucosal proliferation with cribriform pattern, granulomatous lesions in serosa and glandular epithelial invasion of muscularis (see Figure 4A). Granulomas comprising of epitheloid and Langerhans giant cells with areas of caseation seen (see Figure 4B). Stratification of epithelial lining, nuclear overcrowding, few mitotic figures and loss of polarity. Nuclear atypia consist of elongated nuclei with increased nucleo-cytoplasmic ratio in hyperplastic cells (see Figure 4C).

Postoperative period was uneventful and she was started on category-I treatment of Directly observed treatment short course (DOTS). She was asymptomatic on follow up after 3 months, during the therapy and had normal menses. 


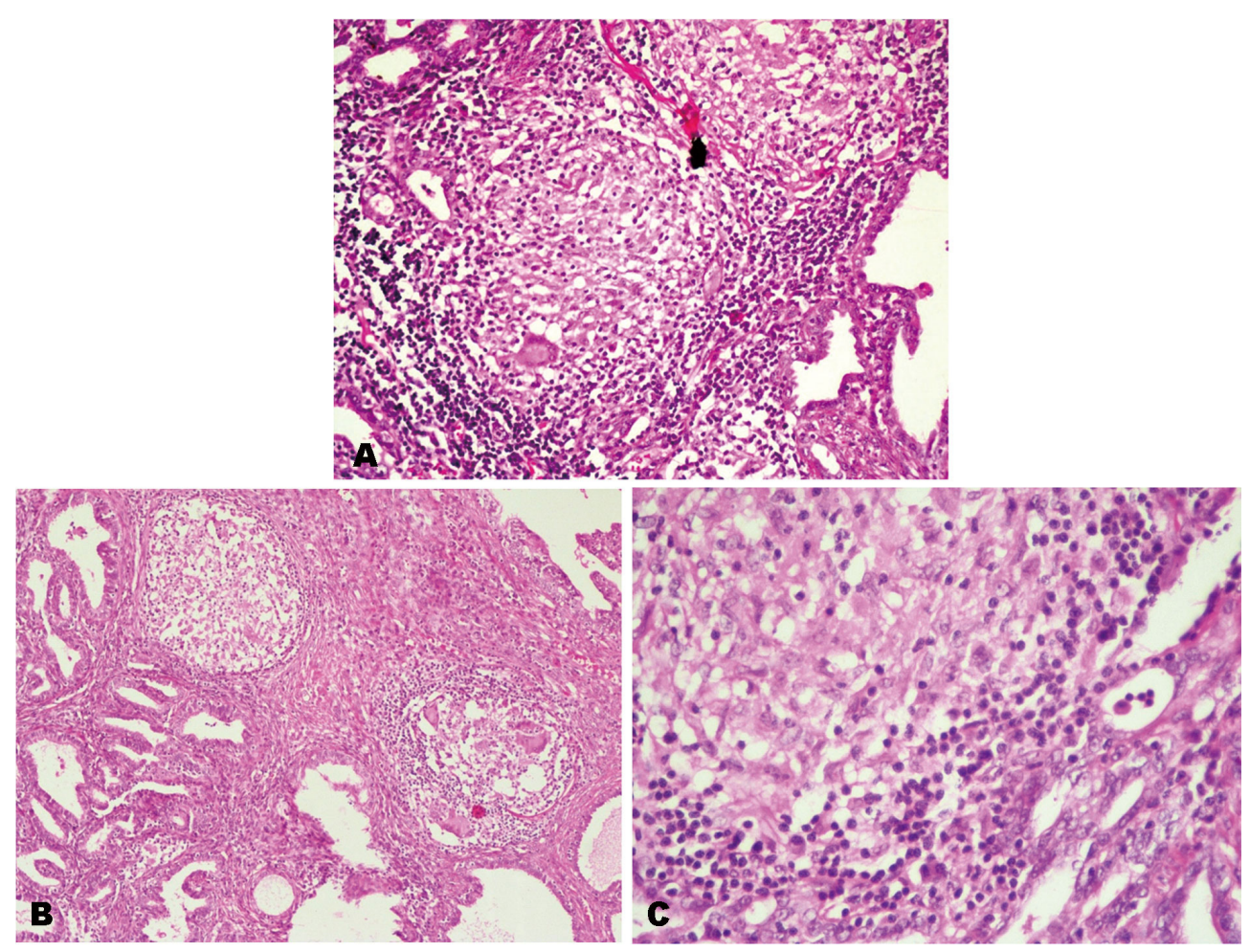

Figure 4. Histopathologial slides showing the features of tuberculous pseudocarcinomatous hyperplasia of fallopian tubes

Our case is rare because usually pseudocarcinomatous hyperplasia is an incidental HPE finding or it causes slight enlargement of tubes, but in our case there was extensive enlargement of tubes that mimicked ovarian neoplasm on examination and radioimaging techniques.

\section{Discussion}

Ovarian neoplasm is typically assumed in a women presenting with adnexal mass, ascites and raised CA-125. But in tropical country like India tuberculous salpingitis should be considered as differential diagnosis in such patients, even if bacteriologic or cytologic studies are negative. Cheng et al. reported that various forms of chronic salpingitis including tubercular may be associated with hyperplastic tubal mucosal lesions, which are at times difficult to distinguish histologically from tubal malignancy. ${ }^{[5]}$ The clinical significance of these hyperplastic mucosal proliferations are controversial, it could be incidental finding with no significance or it could be uncommon lesion associated with malignancy of genital tract. ${ }^{[6,7]}$ Pseudocarcinomatous hyperplasia can be confused with tubal malignancy but it usually occurs in younger age and causes bilateral diffuse enlargement of tubes, which on microscopy show papillary gland like cribriform pattern, lined by epithelial cells with mild to moderate nuclear pleomorphism, loss of polarity, stratification, overcrowding, hyperchromasia, scattered mitotic figures with no invasion. ${ }^{[8]}$ Bagga et al. evaluated ten women in peri and postmenopausal age with suspected ovarian cancer due to adnexal masses, ascites and raised CA-125. They found that seven of them had pelvic-peritoneal tuberculosis that could be diagnosed only after laprotomy, ascetic fluid showed lymphocytic predominance, raised ADA and absence of malignant cells. ${ }^{[9]}$ Pelvic or peritoneal tuberculosis should always be considered as a differential diagnosis in tropical countries like India for abdominopelvic masses. Cytological and histopathological diagnosis should be established by ultrasound or laproscopic guided biopsy or ascitic tap that can avoid unnecessary laprotomy.

\section{Conclusion}

Pseudocarcinomatous hyperplasia is the benign lesion of the tubes that could be incidental finding or may be associated with chronic inflammation and estrogen producing ovarian tumor. Our case is rare as tuberculous Pseudocarcinomatous hyperplasia of tubes lead to extensive enlargement of tubes that mimicked ovarian malignancy clinically and tubal malignancy microscopically. Careful reporting of Radioimaging modalities can help to avoid extensive work up of adnexal mass.

\section{Conflicts of InTERest Disclosure}

The authors declare that they have no conflict of interest related to this manuscript. 


\section{REFERENCES}

[1] Robey SS, Silva EG. Epithelial hyperplasia of the fallopian tube. Its association with serous borderline tumors of the ovary. Int J Gynecol Pathol. 1989; 8(3): 214-20. https://doi.org/10.1097/000043 47-198909000-00004

[2] Cheung AN, Young RH, Scully RE. Pseudocarcinomatous hyperplasia of the fallopian tube associated with salpingitis. A report of 14 cases. Am J Surg Pathol. 1994; 18(11): 1125-30. PMid:7943533 https ://doi.org/10.1097/00000478-199411000-00006

[3] Seshadri Lakshmi. Essentials of gynaecology. New Delhi: Wolters Kluwer India Pvt Ltd. 2012.

[4] Nagpaul DR. Female genital tuberculosis. Indian J Tuberc. 1991; 38(4): 187-88.

[5] Cheung AN, Young RH, Scully RE. Pseudocarcinomatous hyperplasia of the fallopian tube which was associated with salpingitis. A report of 14 cases. Am J Surg Pathol. 1994; 18(11): $1125-$ 30. PMid:7943533 https://doi .org/10.1097/00000478-199 411000-00006
[6] Moore SW, Enterline HT. Significance of proliferative epithelial lesions of the uterine tubes. Obstet Gynecol. 1975; 45: 385-90. PMid:47623

[7] Dallenbach-Hellweg G, Niehoff B. The epithelium of the tubes in correlation with the histological findings in the endometrium and the ovary. Virchows Arch A Pathol Pathol Anat. 1971; 354: 66-79. PMid:4330078 https : //doi .org/10.1007/BF00544108

[8] Gupta S, Singh P, Bala J, et al. Pseudocarcinomatous hyperplasia of the fallopian tubes which was associated with female genital tract tuberculosis, histologically mimicking tubal adenocarcinoma: A diagnostic challenge. J Clin Diagn Res. 2012; 6(8): 1419-21. https ://doi.org/10.7860/jcdr/2012/3931.2375

[9] Bagga R, Muthyala T, Saha SC, et al. Peri and post-menopausal women with complex adnexal masses, ascites, and raised CA-125: Is it ovarian cancer or tuberculosis? J Midlife Health. 2016; 7(4): 193-196. PMid:28096645 https://doi.org/10.4103/0976-7 800.195700 